\title{
The Promotion Effect and Mechanism of Methanoic Acid on the Photoelectrocatalytic Degradation of Fulvic Acid
}

\author{
Yifan Dong, ${ }^{1}$ Jinhua Li, ${ }^{1}$ Xuejin Li, ${ }^{1}$ Jing Bai, ${ }^{1}$ and Baoxue Zhou ${ }^{1,2}$ \\ ${ }^{1}$ School of Environmental Science and Engineering, Shanghai Jiao Tong University, No. 800 Dongchuan Road, Shanghai 200240, China \\ ${ }^{2}$ Key Laboratory for Thin Film and Microfabrication of the Ministry of Education, Shanghai 200240, China \\ Correspondence should be addressed to Jinhua Li; lijinhua@sjtu.edu.cn and Baoxue Zhou; zhoubaoxue@sjtu.edu.cn
}

Received 26 January 2016; Accepted 7 March 2016

Academic Editor: Jun Wu

Copyright (c) 2016 Yifan Dong et al. This is an open access article distributed under the Creative Commons Attribution License, which permits unrestricted use, distribution, and reproduction in any medium, provided the original work is properly cited.

\begin{abstract}
A significant promotion effect of methanoic acid (MA) was proposed in the photoelectrocatalytic (PEC) degradation of fulvic acid (FA) and the degradation mechanism was also discussed. The PEC degradation property of FA and MA was investigated by an assembled thin-layer PEC reactor in which photoanode is $\mathrm{TiO}_{2}$ nanotube arrays (TNAs) material. The result shows that only about $40 \%$ of FA was degraded, while MA could be completely degraded at the same condition. When mixing MA with FA, it shows a significant improvement in the degradation of FA. For instance, $50 \mathrm{mg} / \mathrm{L}$ FA mixed with $45 \mathrm{mg} / \mathrm{L}$ MA could achieve exhausted degradation. The results could be attributed to the promotion effect of MA that enhanced the generation of hydroxyl radicals, which maintain the continuous degradation of both FA and the intermediate products during the PEC process. This study proposed a new way of promoting the PEC degradation of FA as well as removing humus from the polluted water.
\end{abstract}

\section{Introduction}

Fulvic acid (FA) is a primary kind of natural organic matters (NOMs) in the water body $[1,2]$ and it is also a main precursor of disinfection by-products (DBPs), which is known as a kind of harmful materials, leading to carcinogenic, teratogenic, and mutagenic effects [3]. Thus, removing FA from water is urgently needed. However, due to refractory nature of FA, only limited methods can be applied such as granular activated carbon adsorption, enhanced coagulation, and membrane filtration. Among them, even if the enhanced coagulation shows its advantage to restrain large quantity of NOMs including colloid humic acid, it is still ineffective to the soluble FA $[4,5]$.

Recently, the advanced oxidation technologies have been a research's hot spot in removal of NOMs like FA, because it provides hydroxyl radical with strong oxidation ability to decompose organics into small harmless molecules such as $\mathrm{CO}_{2}$ and $\mathrm{H}_{2} \mathrm{O}$ [6-8]. In particular, the photoelectrocatalytic (PEC) technology attracts much more attention due to the remarkable merits, such as low cost, good oxidation ability, high efficiency, and no secondary pollutant [9-11]. However, the PEC technology has been seldom reported to be used in the degradation of FA [12-15].

$\mathrm{TiO}_{2}$ is a semiconductor material, which is widely used as a photoanode in the PEC technology and its excellent performance has been tremendously reported [16-21]. In this study, $\mathrm{TiO}_{2}$ nanotube arrays (TNAs) are chosen as the photoanode material, because they have larger specific surface area, more stable structure, and better PEC properties than the other forms of $\mathrm{TiO}_{2}$. In particular, it could degrade more varieties of refractory organic matter [22-24]. On the other hand, the degradation performance of organics could be influenced by many factors, involving not only the photocatalyst but also the reaction medium. For instance, some chemical matters, such as phosphate, carbonate, and tertiary butyl alcohol, could restrict the activity of hydroxyl radical and further repress the PEC degradation efficiency of organics $[25,26]$.

In the limited previous researches, the feasibility of photocatalytic technology used in the degradation of FA is proved [12-15]. However, the degradation of FA is inefficient and time-consuming, or the preparation of the catalytic material is very complex $[13,14]$. In this study, we proposed 


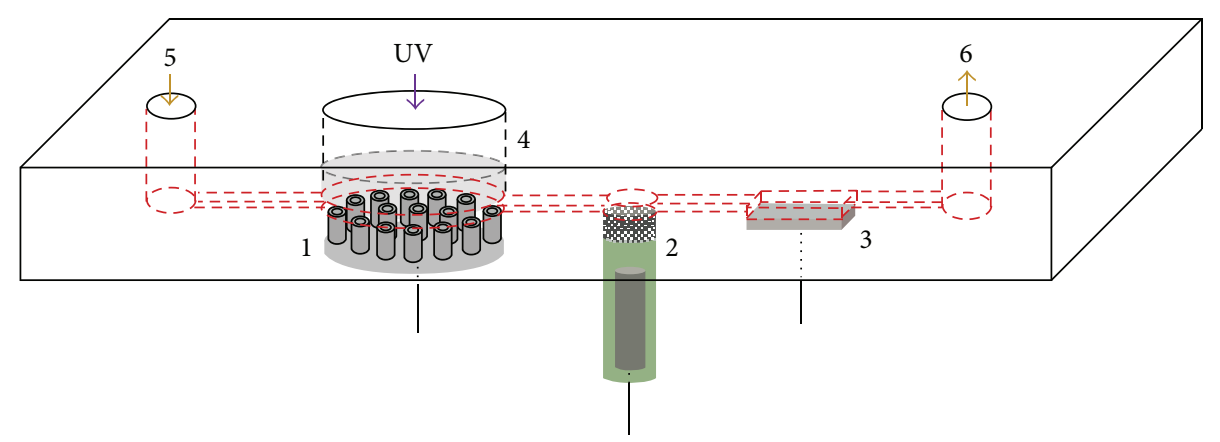

FIGURE 1: The structure of the thin-layer reactor: (1) $\mathrm{TiO}_{2}$ nanotube array electrode; (2) saturated Ag/AgCl reference electrode; (3) Pt counter electrode; (4) quartz window; (5) flow inlet; (6) flow outlet.

a new way of degrading FA using the PEC technology and also investigated the promotion effect of an additive pollutant (methanoic acid, MA) on the degradation of FA. In order to fast and accurately measure the degradation of organics and explore the degradation mechanism, a thin-layer PEC reactor, which has been successfully used in the COD monitoring, was also applied [27, 28].

\section{Materials and Methods}

2.1. Materials. All the reagents in this study were analytically pure and purchased from Sinopharm Chemical Reagent Company (Shanghai, China). All solutions were mixed with high-purity deionized water (18 M $\Omega$ ) purified by a Milli-Q purification system (Millipore Corporation, Billerica, MA). The $\mathrm{NaNO}_{3}$ solution served as a supporting electrolyte in the samples.

2.2. Preparation of the TNA Electrode. The $\mathrm{TiO}_{2}$ nanotube electrodes were prepared by the electrochemical anodic oxidation method, which is reported in our previous work $[28,29]$. In a typical process, the $\mathrm{TiO}_{2}$ nanotube arrays were grown after the potentiostatic anodization at $20 \mathrm{~V}$ using a platinum cathode in a solution of $1 \mathrm{~mol} \cdot \mathrm{L}^{-1} \mathrm{NaHSO}_{4}$, $1 \mathrm{~mol} \cdot \mathrm{L}^{-1} \mathrm{NaF}$, and $0.2 \mathrm{~mol} \cdot \mathrm{L}^{-1}$ trisodium citrate for $6 \mathrm{~h}$. Then as-prepared samples were annealed in a laboratory muffle furnace at $500^{\circ} \mathrm{C}$ for $3 \mathrm{~h}$ to form anatase $\mathrm{TiO}_{2}$ nanotube arrays (TNAs).

2.3. Characterization of TNA Electrode. The phase of TNA electrode was identified by X-ray diffraction (XRD-6100, Shimadzu, Japan), using Cu KR $(\lambda>0.15406 \mathrm{~nm})$ radiation at $40 \mathrm{kV}$ and $30 \mathrm{~mA}$ at a scanning rate of $10^{\circ} / \mathrm{min}$ in the $2 \theta$ range from $10^{\circ}$ to $90^{\circ}$ at room temperature. The surface morphology of TNA electrode was investigated by field emission scanning electron microscopy (Nova NanoSEM 450, FEI Company, USA) under a voltage of $5 \mathrm{kV}$.

2.4. Apparatus and Methods. A thin-layer equipment shown in Figure 1 served as the reactor, where the PEC degradation process was carried out. The thin-layer reactor consists of the following six major sections: the TNAs working electrode, the

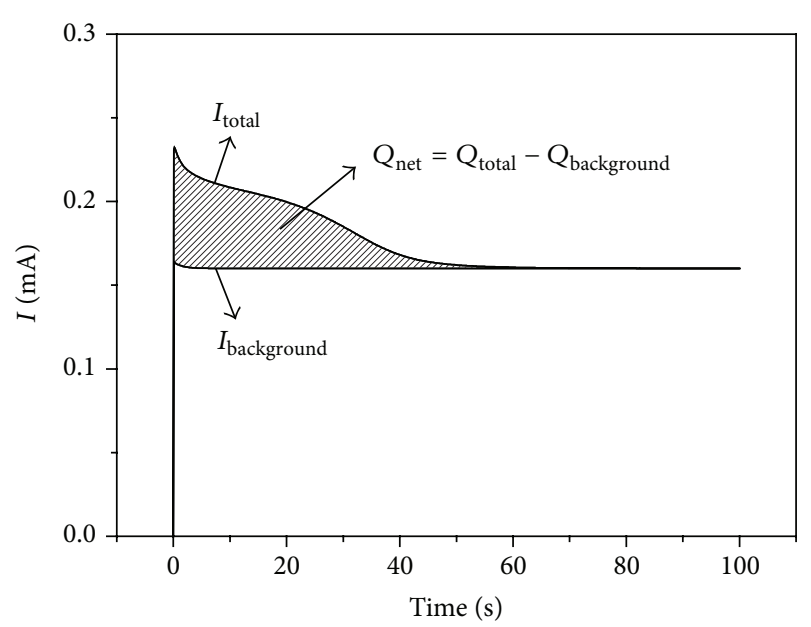

FIgURE 2: The response signals of the PEC degradation.

saturated $\mathrm{Ag} / \mathrm{AgCl}$ reference electrode, the platinum counter electrode, the flow inlet, the flow outlet, and a quartz window with a diameter of $1 \mathrm{~cm}$. The reaction cell in the reactor is built by two coherent polytetrafluoroethylene planks. The cell's thickness was controlled no more than $0.1 \mathrm{~mm}$ in order to reduce the volume of the solution, shorten the time of degradation and the distance of the charge transfer from the solution to the surface of electrode, and ensure the light transmittance in the meanwhile. A $365 \mathrm{~nm}$ ultraviolet LED is chosen to be the light resource. The thin-layer reactor was controlled and monitored by an electrochemical workstation (CHI 610D, Chenghua, Shanghai), which was connected to a computer to record the photocurrent response signals of the PEC degradation.

The degradation rate $(\alpha)$ of organics is determined based on an exhaustive degradation model [27]. In this model, the organics in the thin-cell reactor are rapidly photoelectrocatalytically oxidized and a set of photocurrent-time profiles was then obtained from exhaustive degradation of organics. As shown in Figure 2, photocurrent observed is the sum of two components, one from the oxidation of organics and the other from the oxidation of water $\left(I_{\text {background }}\right)$. The decay of $I_{\text {total }}$ to the $I_{\text {background }}$ level implies that the organics have been partly oxidized and generate the corresponding net charge quantity 




(a)



(b)



(c)

FIgURE 3: FE-SEM top-view (a) and cross-section (b) of TNAs electrode and (c) XRD patterns of TNAs electrode.

$\left(Q_{\text {net }}\right)$. However, under the given condition, the oxidized proportion $\alpha$ should be a constant assuming that the organic compounds could be indiscriminately oxidized. It is possible to obtain $\alpha$ from the ratio of the captured $Q_{\text {net }}$ and theoretical value of the net charge quantity $\left(\mathrm{Th} \mathrm{Q}_{\text {net }}\right)$ of the whole sample, which is well matched with net charge quantity measured by the exhausted oxidation of the whole sample $\left(Q_{\text {net }}\right)$ according to

$$
\alpha=\frac{Q_{\text {net }}}{T h Q_{\text {net }}} .
$$

This method could facilitate the measurement of the degradation rate of different organics according to the amount of electrons.

2.5. Degradation Experiments. $25-100 \mathrm{mg} / \mathrm{L}$ FA and 8$60 \mathrm{mg} / \mathrm{L}$ MA were used as a model pollutant. The PEC experiments were performed in the thin-layer PEC reactors. The supplied voltage, electrolyte concentration, and UV light intensity was controlled in a certain range. The photocatalysis (PC) experiment was performed by using the same system without applying an external potential and the electrolysis (EC) experiment was performed without UV illumination.

\section{Results and Discussion}

3.1. Characterization of Photoanode. The FE-SEM images of the TNAs electrode are shown in Figures 3(a) and 3(b). As can be seen, the nanotubes are highly ordered and well aligned, with the diameter of $\sim 100 \mathrm{~nm}$ and wall thickness of $10 \mathrm{~nm}$ [28]. The cross-section image shows that the nanotubes are $\sim 1.5 \mu \mathrm{m}$ in length and closely combined to the barrier layer. The XRD patterns of the as-annealed TNAs electrode are shown in Figure 3(c). The nanotube without calcinations maintained an amorphous structure in Figure 3(c), B, while the amorphous regions were gradually crystallized to form anatase phases via the calcinations at $500^{\circ} \mathrm{C}$ in Figure 3(c), A. It can be seen from pattern $A$ that the sample possesses characteristic peaks at $25.35^{\circ}(101), 38.1^{\circ}(004)$, and $48.2^{\circ}(200)$ for the anatase phase. The titanium peaks can also be found owing to the Bragg reflection of Ti substrate. 




FIGURE 4: Degradation of $25 \mathrm{mg} / \mathrm{L}$ FA using different process in thinlayer reactor.

3.2. Parameters Affecting the PEC Degradation. The catalytic mode, bias voltage, light intensity, and the concentration of electrolyte are first investigated in order to optimize the PEC degradation. Take $25 \mathrm{mg} / \mathrm{L} \mathrm{FA}$ as an example; various degradation processes were applied including photocatalysis (PC), electrolysis (EC), and photoelectrocatalysis (PEC) and the experimental results are summarized in Figure 4. As can be seen, the photocurrent values of both the PC and EC are much smaller than PEC, implying that both PC and EC mode are ineffective for the degradation of FA. The TNAs electrode has been approved as an excellent photoanode in the previous reports $[27,28]$ since it has an advantage of fast electron transfer. When the given electric bias was supplied to the photocatalyst, it promoted the separation of photogenerated holes and electron. This charge separation could prevent the photoinduced electron and the hole from recombining and consequently lead to higher degradation efficiency. In short, the bias voltage and the UV light illumination have a synergistic effect in the process of PEC degradation.

Table 1 shows the comparison of different bias voltages, light intensity, and electrolyte concentration applied in the PEC process. Based on the measuring method used in this study, $Q_{\text {net }}$ was directly used for analyzing the optimum degradation conditions. In terms of bias voltage, no obvious change of $Q_{n e t}$ is found in the PEC degradation under the bias voltages ranged from $1.0 \mathrm{~V}$ to $2.5 \mathrm{~V}$. However, using a larger bias voltage like $>3.0 \mathrm{~V}$, a deviant increase of $Q_{\text {net }}$ appears possibly due to water electrolysis reaction. Thus, a bias voltage of $2 \mathrm{~V}$ is preferred.

In the process of PEC degradation, the light intensity could influence the speed of the reaction. However, it has no impact on $Q_{\text {net }}$ via the result shown in Table 1. Considering the fact that high light intensity could result in a fast and stable reaction, a light intensity of $37.4 \mathrm{~mW} / \mathrm{cm}^{2}$ was applied for the degradation experiment.
TABLE 1: The relationship between $Q_{\text {net }}$ and parameters affecting the PEC degradation.

\begin{tabular}{lcccccc}
\hline Bias voltage $(\mathrm{v})$ & 1.0 & 1.5 & 2.0 & 2.5 & 3.0 & 3.5 \\
$Q_{\text {net }}(\mathrm{mC})$ & 0.2085 & 0.2100 & 0.2125 & 0.2120 & 0.2250 & 0.2286 \\
\hline $\begin{array}{l}\text { Light intensity } \\
\left(\mathrm{mW} / \mathrm{cm}^{2}\right)\end{array}$ & & 7.4 & 17.4 & 27.4 & 37.4 & 47.4 \\
$Q_{\text {net }}(\mathrm{mC})$ & & 0.2026 & 0.2102 & 0.2107 & 0.2148 & 0.2166 \\
\hline$C_{\text {NaNO3 }}(\mathrm{mol} / \mathrm{L})$ & 0.5 & 1.0 & 1.5 & 2.0 & 2.5 & 3.0 \\
$Q_{\text {net }}(\mathrm{mC})$ & 0.1810 & 0.1982 & 0.2000 & 0.2121 & 0.2129 & 0.2126 \\
\hline
\end{tabular}

The concentration of supporting electrolyte has a direct relationship with the resistance of the solution that could influence the transportation of the photo electrons. As shown in Table 1, the value of $Q_{\text {net }}$ starts to keep stable with the concentration of $\mathrm{NaNO}_{3}$ increasing to over $2.0 \mathrm{~mol} / \mathrm{L}$. Thus, $2.0 \mathrm{~mol} / \mathrm{L} \mathrm{NaNO}_{3}$ solution is used as supporting electrolyte.

In conclusion, the optimum condition used in the following PEC experiment is applied at $2.0 \mathrm{~mol} / \mathrm{L} \mathrm{NaNO}_{3}$ electrolyte, $2 \mathrm{~V}$ bias voltage, and $37.4 \mathrm{~mW} / \mathrm{cm}^{2}$ light intensity.

3.3. The PEC Degradation Property of FA and MA. Figure 5 shows the photocurrent-time profiles and degradation rate $(\alpha)$ of (a), (b) FA and (c), (d) MA, respectively. As can be seen in Figure 5(a), the photocurrent gradually shifted to the right with the increase of FA concentration from 0 (baseline) to $100 \mathrm{mg} / \mathrm{L}$. It indicates that a higher concentration of FA needs a longer degradation time and, accordingly, a larger $Q_{\text {net }}$. The degradation rate $(\alpha)$ of FA can be calculated by (1) based on the photocurrent-time profiles in Figure 5(a). The result shows that $\alpha$ only ranges from $36 \%$ to $41 \%$, indicating only small portion of FA degraded in the PEC process. It can be deduced that most of hydroxyl radicals have been consumed in the beginning of the reaction, while the residual FA and the intermediate products could not be continuously degraded, finally resulting in a lower degradation rate. Thus, we hypothesize that if more hydroxyl radicals were produced in the PEC process, the degradation rate of FA could be improved.

Compared to FA, MA shows a more degradable property. As shown in Figure 5(c), a larger photocurrent can be observed even in a smaller concentration of MA, implying more electrons generated from the degradation of MA. The degradation rate of MA is also calculated based on Figure 5(c). As can be seen from Figure 5(d), the $\alpha$ values of MA at different concentrations are close to $100 \%$, indicating a complete degradation. The excellent degradability of MA is possibly due to its small molecule.

3.4. The Promotion Effect of MA on the Degradation of FA. The promotion effect is investigated by adding different concentrations of MA to $50 \mathrm{mg} / \mathrm{L} \mathrm{FA}$ in the PEC degradation. In this study, $8,15,30,45$, and $60 \mathrm{mg} / \mathrm{L}$ of MA were used. Figure 6(a) shows the photocurrent-time profiles obtained from the PEC degradation of FA mixed with different concentrations of MA. The total $Q_{n e t}$ of the mixture was calculated, respectively. Because MA can be completely 


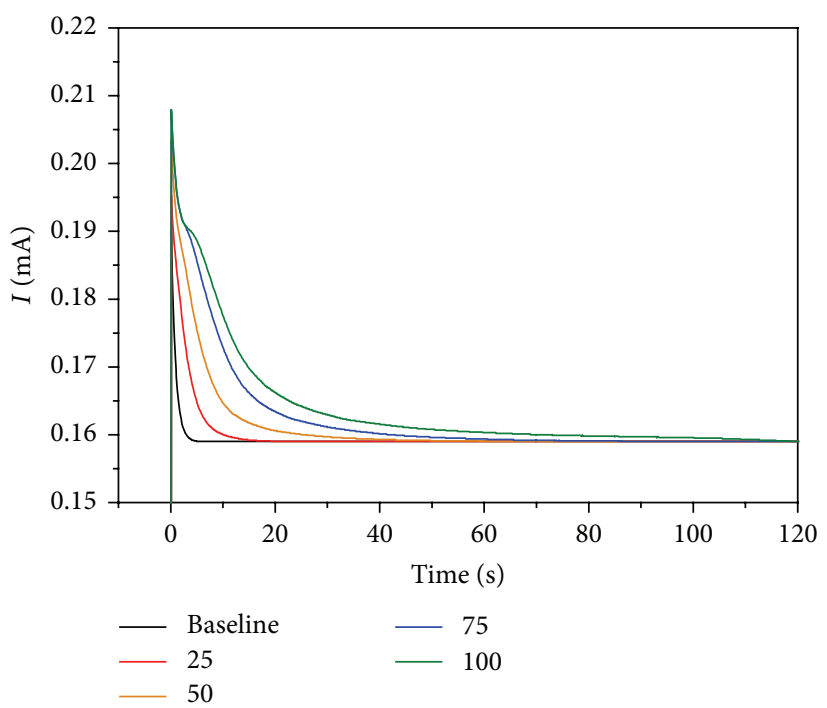

(a)

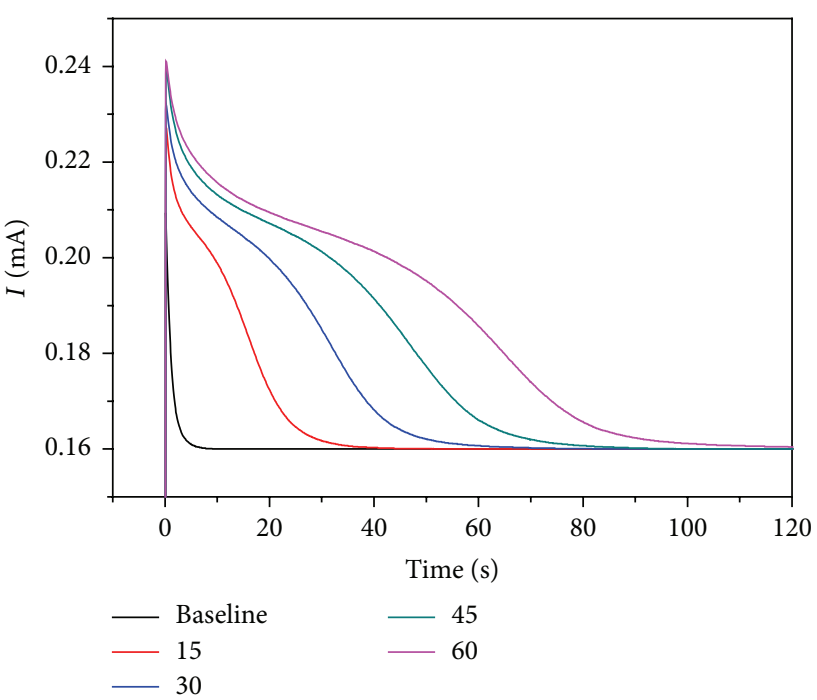

(c)

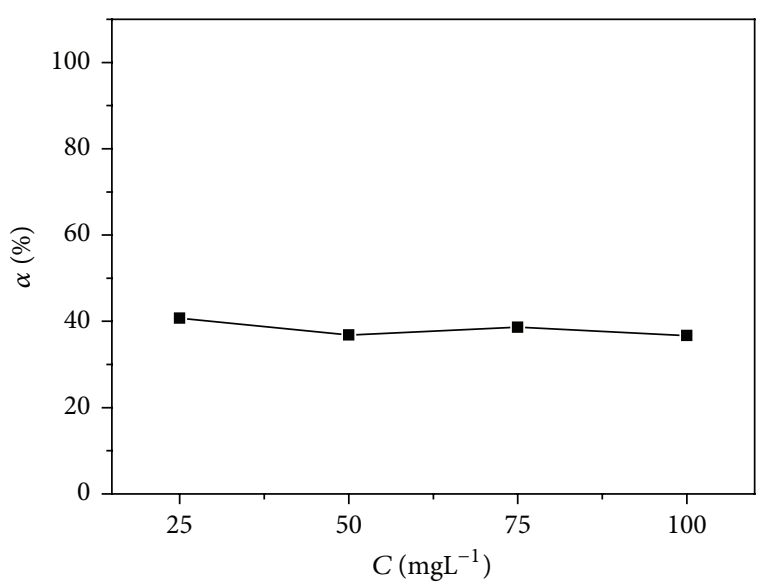

(b)

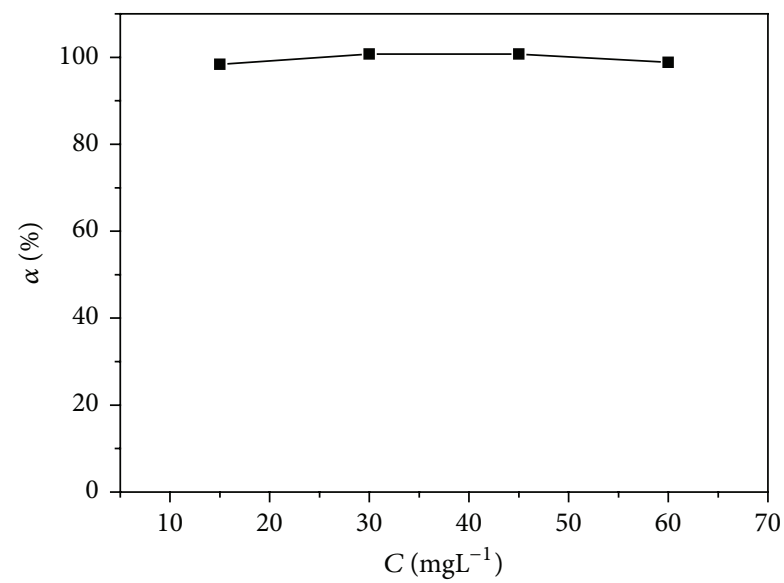

(d)

Figure 5: The photocurrent-time profiles and degradation rate ( $\alpha$ ) of (a), (b) FA and (c), (d) MA.

degraded, $Q_{\text {net-MA }}$ should be equal to $T h Q_{\text {net-MA }}$. Therefore, $Q_{\text {net-FA }}$ could be calculated by subtracting $T h Q_{\text {net-MA }}$ from the total $Q_{\text {net }}$, and then the degradation rates $(\alpha)$ of FA could be calculated according to (1). As shown in Figure 6(b), $\alpha$ increases from $40 \%$ to $100 \%$ with the increase of MA concentration from 0 to $60 \mathrm{mg} / \mathrm{L}$. Obviously, MA has a promotion effect on the PEC degradation of FA. For example, when $45 \mathrm{mg} / \mathrm{L}$ MA was added, $\alpha$ of $50 \mathrm{mg} / \mathrm{L}$ FA reaches $100 \%$. In other words, more than $45 \mathrm{mg} / \mathrm{L}$ additional MA could promote the complete degradation of $50 \mathrm{mg} / \mathrm{L}$ FA.

The mechanism was also discussed herein. As known, TBA is a researched hydroxyl radial scavenger $[25,26]$, which can reduce the concentration of hydroxyl radial. Take the mixture of $50 \mathrm{mg} / \mathrm{L}$ FA and $45 \mathrm{mg} / \mathrm{L} \mathrm{MA}$ as an example; different concentrations of tert-butyl alcohol (TBA) were added to the mixture and the result was shown in Figure 7. As can be seen, $\alpha$ of the mixture obviously reduces with the increase of TBA concentration. As $30 \mathrm{mg} / \mathrm{L}$ TBA is added, $\alpha$ reduces about $10 \%$. This is because the promotion effect of MA on the PEC degradation of FA is restrained when the amount of hydroxyl radial is limited. Thus, it could be deduced that an enormous amount of hydroxyl radicals is generated because of the excellent degradability of MA. The additional hydroxyl radicals could continuously degrade both FA and the intermediate products in the degradation reaction.

\section{Conclusion}

In this study, an obvious promotion effect of MA on the PEC degradation of FA was observed. The degradation rate of FA alone is only about $40 \%$, while it could be significantly improved by addition of MA. With $45 \mathrm{mg} / \mathrm{L}$ MA mixed with $50 \mathrm{mg} / \mathrm{L} \mathrm{FA}$, the degradation rate of FA can achieve $100 \%$. The 


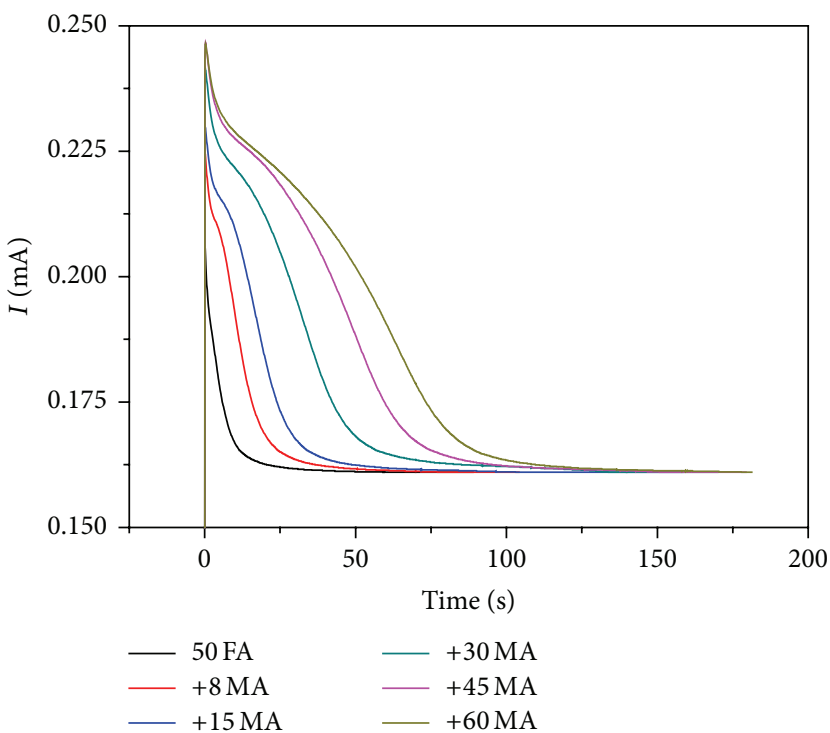

(a)



(b)

Figure 6: The (a) photocurrent-time signals and (b) degradation rate of FA added MA.

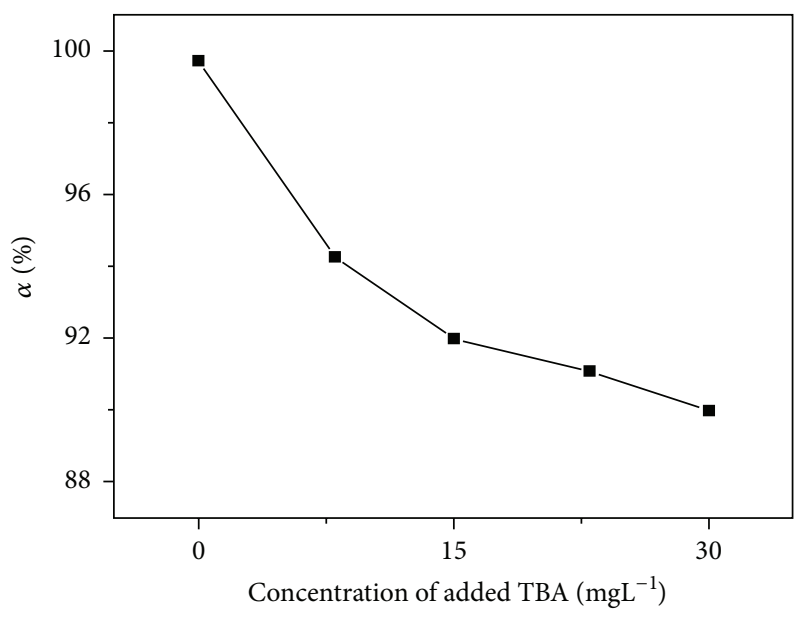

FIGURE 7: The degradation rate of the mixture.

mechanism is also investigated where the enormous amount of hydroxyl radicals, which is generated in the degradation of MA, could maintain the continuous degradation of both FA and the intermediate products. This work provides a new way to promote the PEC degradation of FA and a direction to remove humus from polluted water.

\section{Competing Interests}

The authors declare that there are no competing interests regarding the publication of this paper.

\section{Acknowledgments}

The authors would like to acknowledge the National High Technology Research and Development Program of China
(Grant no. 2009AA063003), the National Nature Science Foundation of China (no. 20677039), and Chinese National Key Projects of Water Pollution and Reclamation (no. 2012ZX07102-002) for financial support.

\section{References}

[1] H. Ødegaard, B. Eikebrokk, and R. Storhaug, "Processes for the removal of humic substances from water-an overview based on Norwegian experiences," Water Science and Technology, vol. 40, no. 9, pp. 37-46, 1999.

[2] B.-Y. Gao and Q.-Y. Yue, "Natural organic matter (NOM) removal from surface water by coagulation," Journal of Environmental Sciences, vol. 17, no. 1, pp. 119-122, 2005.

[3] Y. Wang, R. Mao, Q. Wang, Z. Yang, B. Gao, and Y. Zhao, "Fulvic acid removal performance and control of disinfection byproduct formation potential in coagulation-ultrafiltration process," Desalination, vol. 302, pp. 55-64, 2012.

[4] N. A. Klymenko, I. P. Kozyatnyk, and L. A. Savchyna, "Removing of fulvic acids by ozonation and biological active carbon filtration," Water Research, vol. 44, no. 18, pp. 5316-5322, 2010.

[5] S.-G. Wang, X.-W. Liu, W.-X. Gong, W. Nie, B.-Y. Gao, and Q.-Y. Yue, "Adsorption of fulvic acids from aqueous solutions by carbon nanotubes," Journal of Chemical Technology and Biotechnology, vol. 82, no. 8, pp. 698-704, 2007.

[6] R. Andreozzi, V. Caprio, A. Insola, and R. Marotta, "Advanced oxidation processes (AOP) for water purification and recovery," Catalysis Today, vol. 53, no. 1, pp. 51-59, 1999.

[7] I. Sirés, E. Brillas, M. A. Oturan, M. A. Rodrigo, and M. Panizza, "Electrochemical advanced oxidation processes: today and tomorrow. A review," Environmental Science and Pollution Research, vol. 21, no. 14, pp. 8336-8367, 2014.

[8] H. Fang, Y. Gao, G. Li et al., "Advanced oxidation kinetics and mechanism of preservative propylparaben degradation in aqueous suspension of $\mathrm{TiO}_{2}$ and risk assessment of its degradation products," Environmental Science and Technology, vol. 47, no. 6, pp. 2704-2712, 2013. 
[9] M. N. Chong, B. Jin, C. W. K. Chow, and C. Saint, "Recent developments in photocatalytic water treatment technology: a review," Water Research, vol. 44, no. 10, pp. 2997-3027, 2010.

[10] M. A. Oturan and J.-J. Aaron, "Advanced oxidation processes in water/wastewater treatment: principles and applications. A review," Critical Reviews in Environmental Science and Technology, vol. 44, no. 23, pp. 2577-2641, 2014.

[11] M. Antonopoulou, E. Evgenidou, D. Lambropoulou, and I. Konstantinou, "A review on advanced oxidation processes for the removal of taste and odor compounds from aqueous media," Water Research, vol. 53, pp. 215-234, 2014.

[12] B. A. Nerger, R. H. Peiris, and C. Moresoli, "Fluorescence analysis of NOM degradation by photocatalytic oxidation and its potential to mitigate membrane fouling in drinking water treatment," Chemosphere, vol. 136, pp. 140-144, 2015.

[13] S. Sen Kavurmaci and M. Bekbolet, “Tracing $\mathrm{TiO}_{2}$ photocatalytic degradation of humic acid in the presence of clay particles by excitation-emission matrix (EEM) fluorescence spectra," Journal of Photochemistry and Photobiology A: Chemistry, vol. 282, pp. 53-61, 2014.

[14] Q. Zhou, Y.-H. Zhong, X. Chen, J.-H. Liu, X.-J. Huang, and Y.C. $\mathrm{Wu}$, "Adsorption and photocatalysis removal of fulvic acid by $\mathrm{TiO}_{2}$-graphene composites," Journal of Materials Science, vol. 49, no. 3, pp. 1066-1075, 2014.

[15] D. Wang, Y. Li, G. Li Puma et al., "Mechanism and experimental study on the photocatalytic performance of $\mathrm{Ag} / \mathrm{AgCl} @$ chiral $\mathrm{TiO}_{2}$ nanofibers photocatalyst: the impact of wastewater components," Journal of Hazardous Materials, vol. 285, pp. 277-284, 2015.

[16] J. Pei, W. Ma, R. Li, Y. Li, and H. Du, "Preparation and photocatalytic properties of $\mathrm{TiO}_{2}-\mathrm{Al}_{2} \mathrm{O}_{3}$ composite loaded catalysts," Journal of Chemistry, vol. 2015, Article ID 806568, 7 pages, 2015.

[17] D. T. Sponza and R. Oztekin, "Photodegradation of polyphenols and aromatic amines in olive mill effluents with $\mathrm{Ni}$ doped $\mathrm{C} / \mathrm{TiO}_{2}$," Journal of Chemistry, vol. 2015, Article ID 276768, 12 pages, 2015.

[18] C. Basheer, "Application of titanium dioxide-graphene composite material for photocatalytic degradation of alkylphenols," Journal of Chemistry, vol. 2013, Article ID 456586, 10 pages, 2013.

[19] L. Prieto-Rodríguez, I. Oller, N. Klamerth, A. Agüera, E. M. Rodríguez, and S. Malato, "Application of solar AOPs and ozonation for elimination of micropollutants in municipal wastewater treatment plant effluents," Water Research, vol. 47, no. 4, pp. 1521-1528, 2013.

[20] T. An, J. Chen, X. Nie et al., "Synthesis of carbon nanotubeanatase $\mathrm{TiO}_{2}$ sub-micrometer-sized sphere composite photocatalyst for synergistic degradation of gaseous styrene," ACS Applied Materials and Interfaces, vol. 4, no. 11, pp. 5988-5996, 2012.

[21] A. Ajmal, I. Majeed, R. N. Malik, H. Idriss, and M. A. Nadeem, "Principles and mechanisms of photocatalytic dye degradation on $\mathrm{TiO}_{2}$ based photocatalysts: a comparative overview," RSC Advances, vol. 4, no. 70, pp. 37003-37026, 2014.

[22] Q. Zheng, B. Zhou, F. Bai et al., "Self-organized $\mathrm{TiO}_{2}$ nanotube array sensor for the determination of chemical oxygen demand," Advanced Materials, vol. 20, no. 5, pp. 1044-1049, 2008.

[23] X. Huangfu, Y. Wang, Y. Liu et al., "Effects of humic acid and surfactants on the aggregation kinetics of manganese dioxide colloids," Frontiers of Environmental Science and Engineering, vol. 9, no. 1, pp. 105-111, 2014.
[24] C. Basheer, "Nanofiber-membrane-supported $\mathrm{TiO}_{2}$ as a catalyst for oxidation of benzene to phenol," Journal of Chemistry, vol. 2013, Article ID 562305, 7 pages, 2013.

[25] J. Staehelin and J. Hoigne, "Decomposition of ozone in water in the presence of organic solutes acting as promoters and inhibitors of radical chain reactions," Environmental Science and Technology, vol. 19, no. 12, pp. 1206-1213, 1985.

[26] N. H. Ince, I. Gültekin, and G. Tezcanli-Güyer, "Sonochemical destruction of nonylphenol: effects of $\mathrm{pH}$ and hydroxyl radical scavengers," Journal of Hazardous Materials, vol. 172, no. 2-3, pp. 739-743, 2009.

[27] X. Li, J. Li, J. Bai, Y. Dong, L. Li, and B. Zhou, "The inhibition effect of tert-butyl alcohol on the $\mathrm{TiO}_{2}$ nano assays photoelectrocatalytic degradation of different organics and its mechanism," Nano-Micro Letters, 2016.

[28] X. Li, W. Yin, J. Li et al., " $\mathrm{TiO}_{2}$ nanotube sensor for online chemical oxygen demand determination in conjunction with flow injection technique," Water Environment Research, vol. 86, no. 6, pp. 532-539, 2014.

[29] Q. Cai, M. Paulose, O. K. Varghese, and C. A. Grimes, "The effect of electrolyte composition on the fabrication of self-organized titanium oxide nanotube arrays by anodic oxidation," Journal of Materials Research, vol. 20, no. 1, pp. 230-236, 2011. 

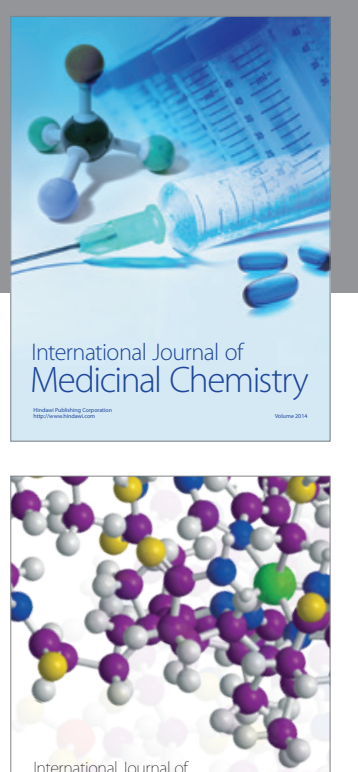

Carbohydrate Chemistry



The Scientific World Journal
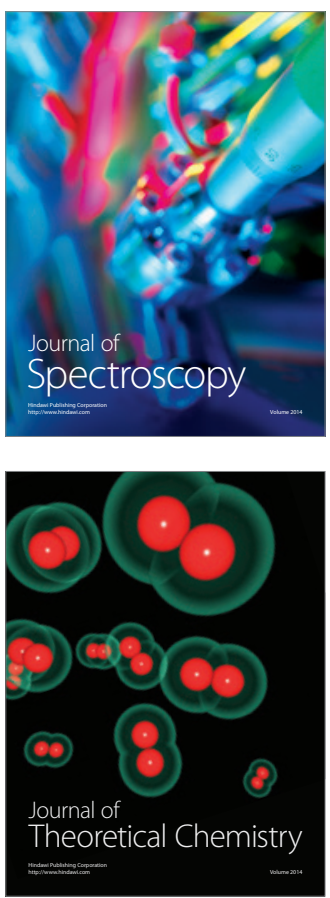
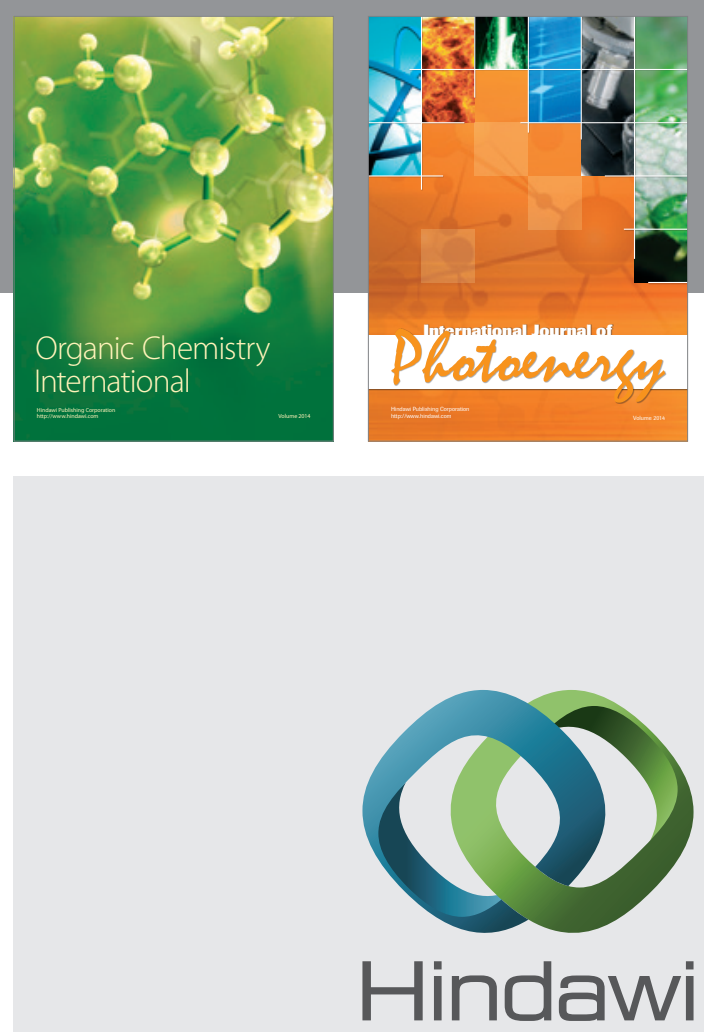

Submit your manuscripts at

http://www.hindawi.com



International Journal of

Inorganic Chemistry



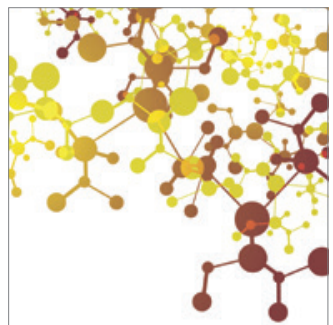

Applied Chemistry
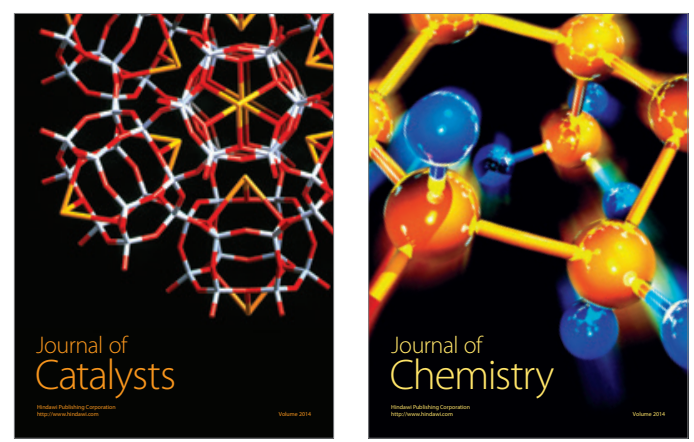
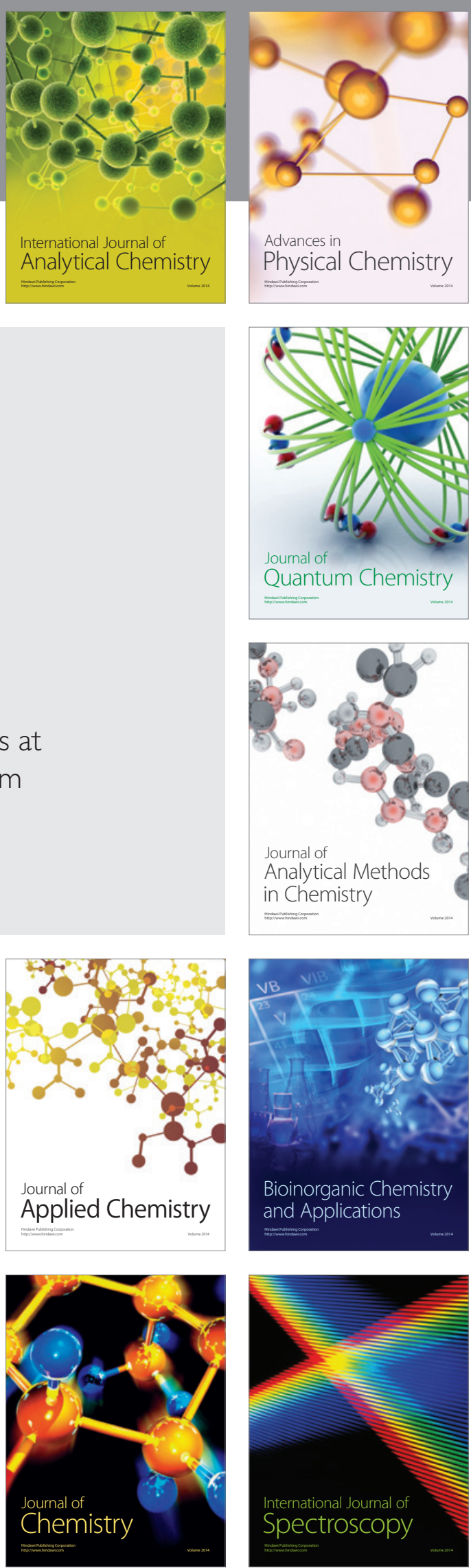